\title{
Entre la Arcadia y el amor cortés, un paisaje de Jan Wildens
}

\author{
Between the Arcady and the courtly love, a landscape by Jan Wildens
}

\author{
Matías Díaz Padrón ${ }^{1}$ \\ Instituto Moll. Centro de Investigación de Pintura Flamenca
}

Resumen: La autoría de un exquisito paisaje con figuras en un ambiente festivo se restituye a Jan Wildens, pintor flamenco que colaboró con Rubens en varias ocasiones. La restauración de esta obra ha contribuido a su valoración y a su correcta catalogación.

Palabras clave: Jan Wildens; Pedro Pablo Rubens; paisaje; Siglo XVII; pintura; amor cortés.

\begin{abstract}
The authorship of a stylish landscape with figures in a festive atmosphere is returned to Jan Wildens, a Flemish painter who usually collaborated with Rubens. The restauration has contributed to assess and catalog this work properly.
\end{abstract}

Keywords: Jan Wildens; Peter Paul Rubens; landscape; 17th century; painting; courtly love.

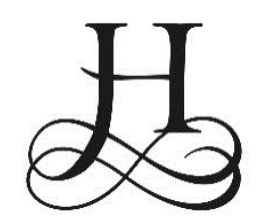

oy tenemos motivos para restituir a Jan Wildens el paisaje con un grupo de jóvenes en alegre compañía, donde la música, el licor y los manjares contribuyen al encanto del momento (L. $79,3 \times 120,7$ cm.) (fig. 1). La exquisita factura, el dibujo y el color han contribuido a la autoría propuesta por nosotros, frente a las dudas de la galería Sotheby's de Londres (2001-VII12 , no 103). La monografía que Wolfgang Adler le dedica al pintor nos ha dado suficientes argumentos visuales a través de las pinturas y dibujos

\footnotetext{
${ }^{1}$ http://orcid.org/ 0000-0002-5137-7583

(C) 2018 Philostrato. Revista de Historia y Arte
} 
reproducidos para apoyar esta nueva catalogación ${ }^{2}$. Una bucólica visión de la naturaleza, en la que se combinan las influencias del norte y sur europeos, así como la fundamental de Pedro Pablo Rubens, pintor con quien colabora Jan Wildens y a quien copia en composiciones de gran aparato, sin olvidar a otros maestros de historias, cacerías y animales con quienes también trabajó Wildens y que también influyeron en su obra final.

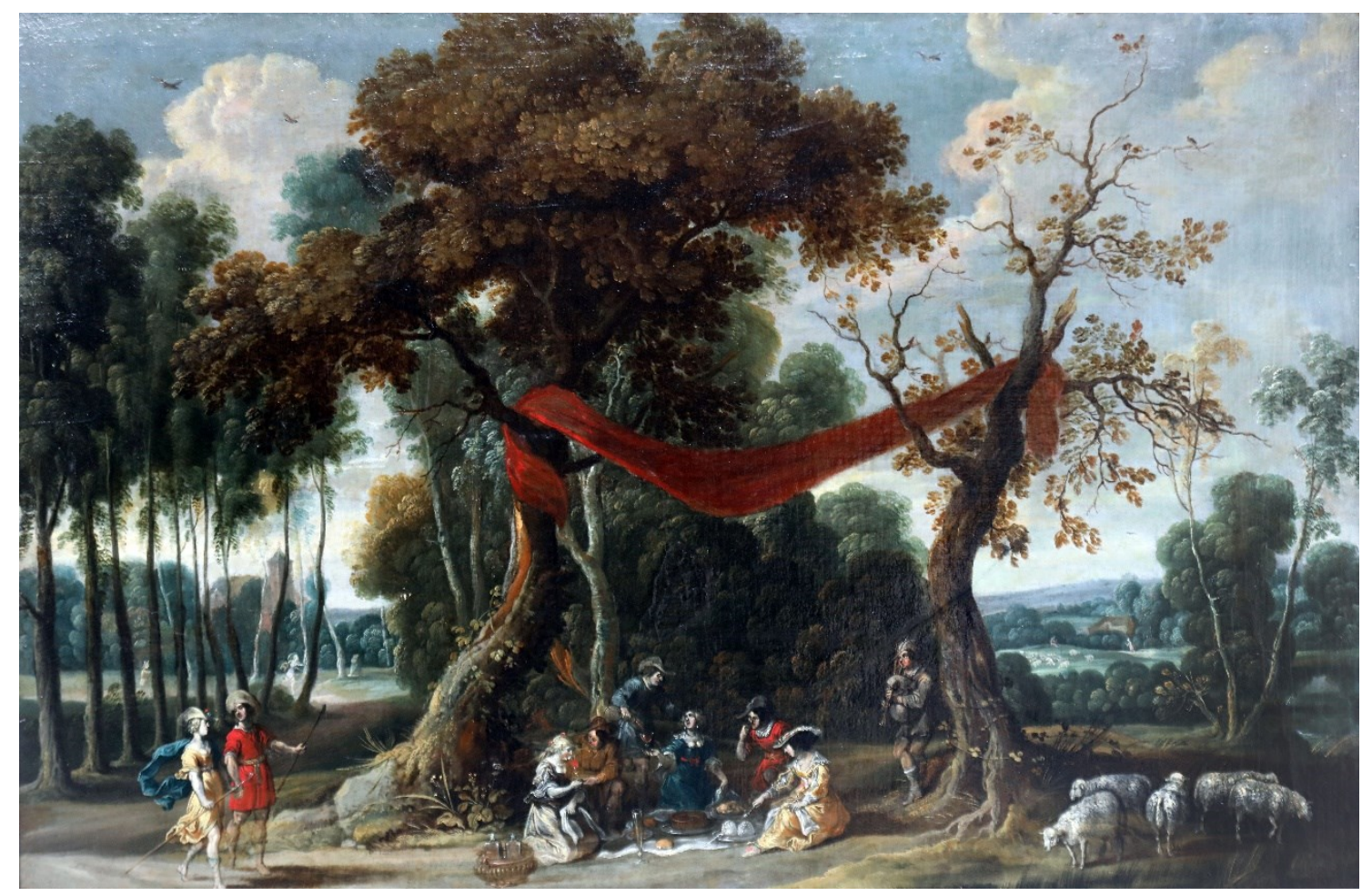

Fig. 1. Jan Wildens, Paisaje con jóvenes merendando, Valencia, colección EpiarteC

La escena central de este paisaje presenta un encuentro fuera del bullicio de la ciudad, en una verde pradera de suave y armónica simetría. La compensación de las masas y la cuidada ejecución le distingue de Rubens. Wildens conjuga aquí el realismo con una extrema atención a los detalles, que despliega con generosidad y gracia en los últimos planos del horizonte, fundiéndolos sutilmente en la atmósfera. A diferencia de Rubens, impone el dominio de una simetría en escala cadente desde el primer plano hasta la lejanía. En relación con las formulaciones de Jan Brueghel y Paul Brill, pintor, éste último, a quien no fue indiferente Wildens durante su viaje a Italia.

Es un paisaje que evoca las tierras fértiles de Flandes, con árboles robustos en el primer plano y otros en acusada verticalidad a la izquierda del horizonte, bajo suaves hondonadas. El centro lo ocupa un grupo de jóvenes parejas merendando en animada conversación (fig. 2). Dos viejos troncos modelados por el viento y el paso de los años sirven de apoyo a una

2 Wolfgang Adler, Jan Wildens. Der Landschaftsmitarbeiter des Rubens, (Fridingen: Graf Klenau Verlags $\mathrm{GmbH}, 1980$ ). 
tela roja que protege del sol y de la lluvia a los allí reunidos. Bajo su sombra están los jóvenes en feliz encuentro. Sirve de fondo la tupida vegetación del arbolado bajo un horizonte de nubes en el cielo azul. Armoniza el espacio el terreno en horizontal con la masa de árboles tan del gusto de la estética de Jan Wildens.

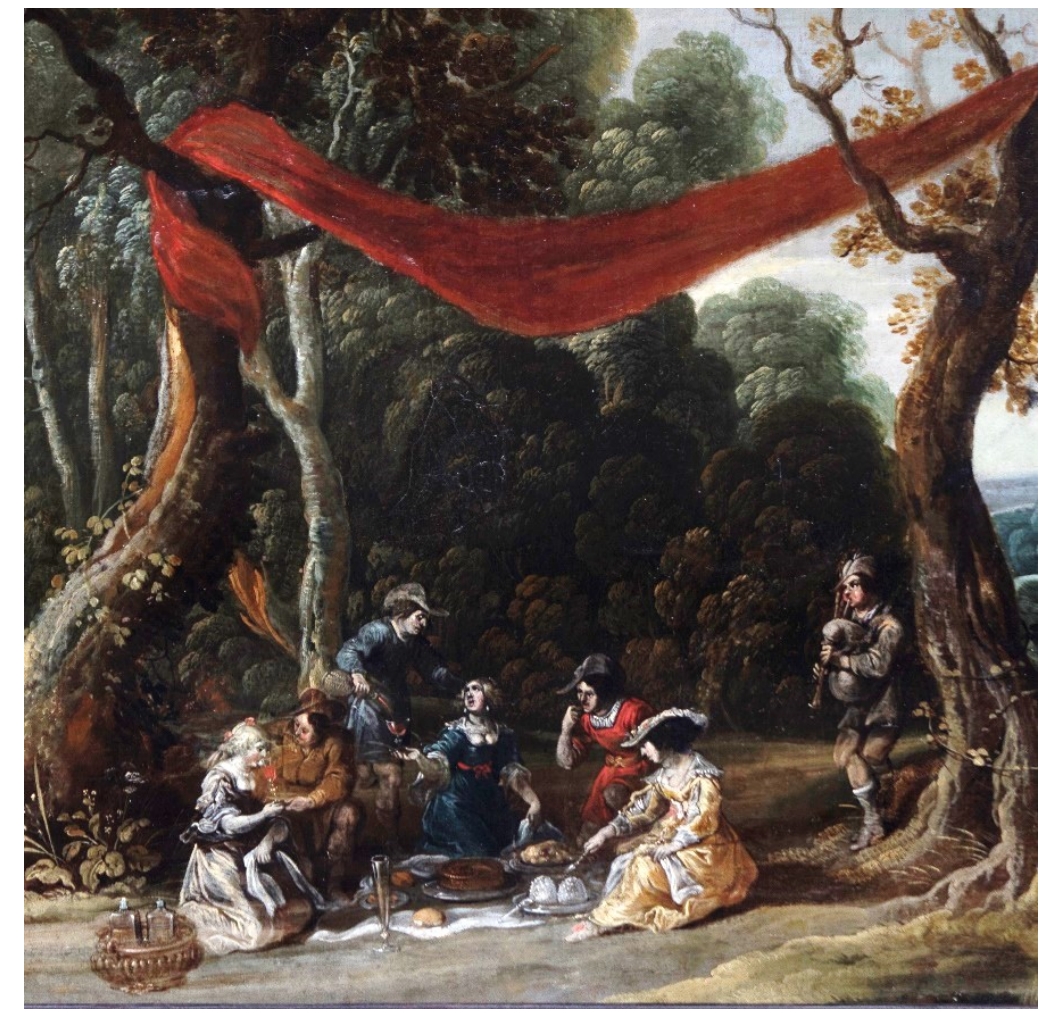

Fig. 2. Jan Wildens, Detalle central de Paisaje con jóvenes merendando, Valencia, colección EpiarteC

Una segunda franja de árboles tupidos, paralela al horizonte, deja sitio a minúsculas escenas con juegos lúdicos y un pastor que descansa con el rebaño. Los del último plano son prolongación de las ovejas agrupadas en la parte derecha del lienzo. La fértil campiña está bañada por la luz del atardecer estival, luz que filtra sus rayos entre las ramas y hojas del bosque, en uniforme tonalidad espacial.

Jan Wildens integra una escena de género en el paisaje. Ningún mensaje de signo devoto ni mitológico se pretende aquí. Es una visión del vivir cotidiano y desenfadado de Flandes. Los jóvenes han escapado de la ciudad al campo sin más pretensiones que sentir la paz y el encanto de la naturaleza. Los alimentos, los licores y los utensilios del primer plano nos ofrecen un interesante documento culinario de la época: aquí está un enfriador con diversas botellas en primer plano, una copa de desproporcionado tamaño y una bandeja ricamente repujada. Un ostentoso menaje propio de las circunstancias: un encuentro de damas y caballeros corteses. Un músico toca una gaita para deleite de los sentidos, apoyado en el tronco de un árbol. 
No es difícil ver en esta reunión campestre ecos de El Jardín del Amor de Peter Paul Rubens del Museo del Prado (inv. no P01690), tan divulgado en copias y grabados de la época. Como se ha señalado, Jan Wildens fue colaborador y discípulo de Rubens. A la influencia del maestro en esta pintura habría que añadir otras referencias de signo literario y poético, con

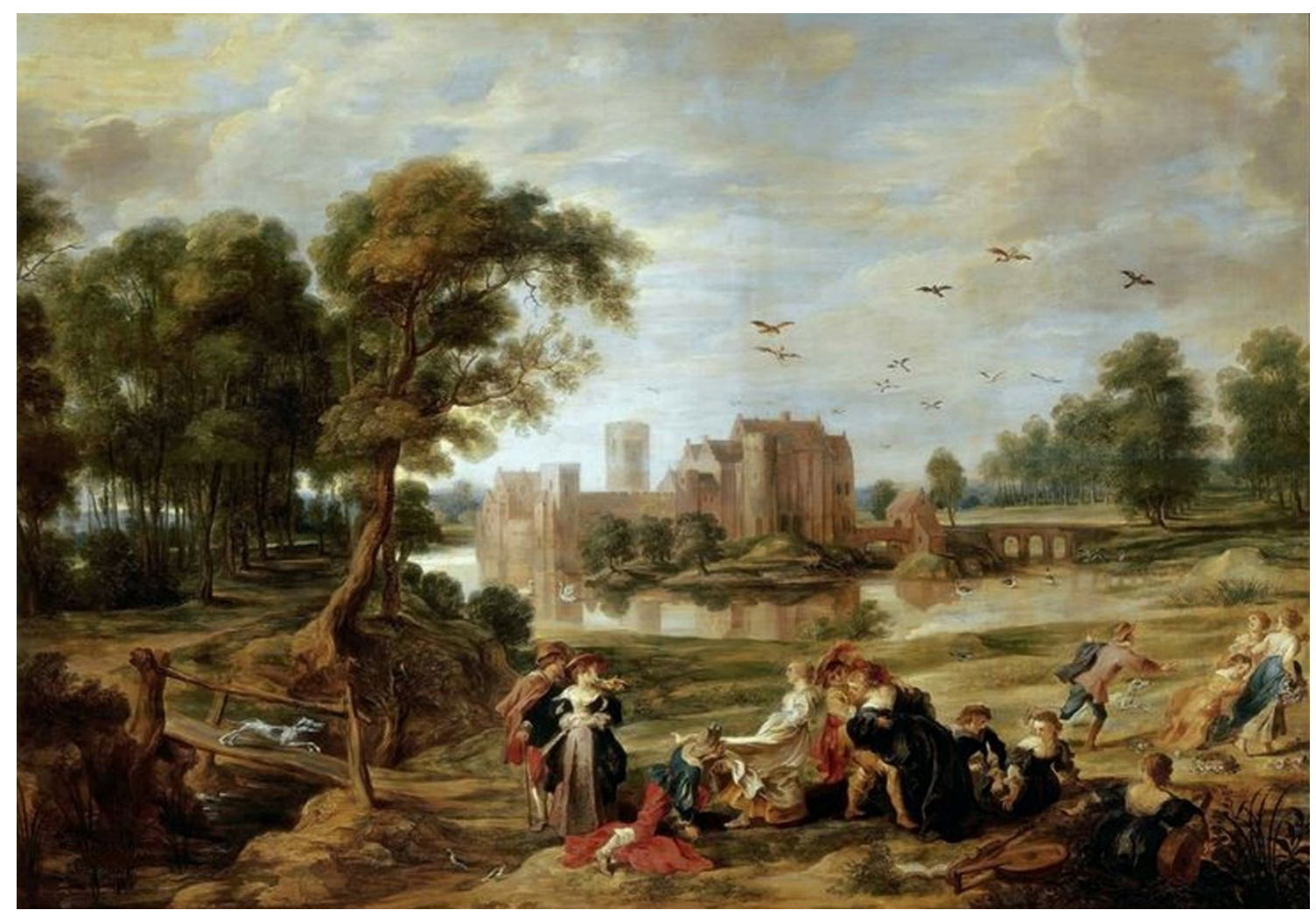

Fig. 3. Peter Paul Rubens, El Jardín del Amor, colección privada

el Amor como eje del encuentro. Es una llamada a la Arcadia literaria. El pintor nos transmite el placer del encuentro campestre de los jóvenes en las miradas y los gestos de los convidados, completamente ajenos al espectador. Nada distrae su jovial alegría, lejos del "mundanal ruido" como cantaba fray Luis de León en su poema a la Vida retirada.

Más próximas que El Jardín del Amor del Museo del Prado, son las versiones del mismo asunto en el Kunsthistorisches Museum de Viena (inv. no 679), atribuido a Victor Wolvoet $\mathrm{II}^{3}$, y el de Rubens de colección privada (fig. 3). Aquí también la composición se desplaza en horizontal, con la música representada por un laúd en tierra y la gracia del movimiento de cada pareja. Dos jóvenes se aproximan desde la izquierda, igual que en el lienzo objeto de este estudio. En fin, la misma voluntad artística vive en una y otra pintura. Hombres y mujeres reviven en el encanto de la naturaleza.

${ }^{3}$ La pintura procede de la propia colección del pintor, donde figura en su inventario postmortem en 1652 (n०530). 
Escasas son las repeticiones en la producción de Jan Wildens. Así, pocas analogías con otras obras pueden verse más allá de la distribución de las masas en la composición. Esto vemos en Mercurio y Hersé del Museo del Prado (inv. no P02733), con la colaboración de Frans Francken II. Aquí, igual que en la reunión de Jan Wildens, una pareja avanza del lado izquierdo hacia el grupo que degusta el banquete. El paisaje es más espacioso, pero son similares la distribución de los árboles y de las ramas, con hojas lánguidas y sin savia de vida.

La misma idea se ve en los paisajes de Wildens del Palazzo Bianco de Génova, del Koninklijkmuseum de Amberes y de la Rubenshuis. Especial interés tienen, en este breve análisis comparativo, el diseño de los árboles del fondo y las figuras de mayor tamaño del paisaje con jóvenes merendando de la Rubenshuis. Igualmente, destacan el modelo de los árboles en el Acto de devoción de Rodolfo I de Habsburgo, del Museo del Prado (inv. no P01645), obra realizada en colaboración con Rubens, y las copias del mismo Jan Wildens en la Sint-Waldetrudiskerk de Herentals y en colección privada de Londres. A estos, se suman los paisajes de Frankfurt, de la colección Girardet y de la Rubenshuis. El árbol más grueso y retorcido del paisaje aquí estudiado es similar al dibujo de la colección Hervert Girardet.

Para finalizar, se hacen unas pequeñas precisiones en cuanto al estado de conservación de la pintura. El Paisaje con jóvenes merendando tiene dos inscripciones en el reverso, sobre el bastidor: en el centro y escrito a mano con tinta negra, el no 3; y en el travesaño inferior, H410512/1OMP, escrito a mano con cera de color amarillo. Además, tiene seis etiquetas de la casa de subastas londinense donde se adquirió. El lienzo llegó a la colección actual sin reentelar, aspecto que tuvo que ser subsanado, pues la preservación correcta de la obra exigía su forración. El bastidor era el original. La escasa adhesión de la preparación y de la pintura obligó al sentado del color. La pesada capa de excrecencias, los barnices oxidados y los repintes impedían apreciar la notable calidad y finura cromática de su estilo. Esto, posiblemente, motivó las reservas de la galería londinense para reconocer su correcta autoría. Se estucaron las escasas y pequeñas lagunas y se procedió a su reintegración. Finalmente, la limpieza permitió valorar las exquisitas tonalidades de los verdes y azules en contraste con el rojo ardiente de la tela que cubre la reunión de los comensales. 
Bibliografía

Adler 1980: Wolfgang Adler, Jan Wildens. Der Landschaftsmitarbeiter des Rubens, (Fridingen: Graf Klenau Verlags GmbH, 1980).

Recibido: 01/06/2018

Aceptado: $18 / 06 / 2018$ 